\title{
A Cross Sectional Study to Assess the Awareness, Knowledge and Practice towards Implant Protocols Followed by Dental Professionals during Covid-19 Pandemic
}

\author{
Champa Talreja ${ }^{1}$, Sharin Issac ${ }^{2}$, Suresh Nagaral $^{3}$, Girija Dodamani ${ }^{4}$, \\ Mahesh Gandhewar ${ }^{5}$ \\ ${ }^{1,2}$ Post Graduate Student, Department of Prosthodontics Crown and Bridge, JMF'S ACPM Dental College, \\ Dhule, Maharashtra. \\ ${ }^{3}$ Professor, Department of Prosthodontics Crown and Bridge, JMF'S ACPM Dental College Dhule, \\ Maharashtra. \\ ${ }^{4}$ Reader, Department of Prosthodontics Crown and Bridge, JMF'S ACPM Dental College Dhule, Maharashtra. \\ ${ }^{5}$ Head of Department, Department of Prosthodontics Crown and Bridge, JMF'S ACPM Dental College Dhule, \\ Maharashtra. \\ Corresponding Author: Champa Talreja
}

DOI: https://doi.org/10.52403/ijhsr.20220307

\begin{abstract}
Background: SARS-COV2, the virus also popularly known as the Coronavirus is an RNA- based virus that came to light in December 2019 when China informed the World Health Organization about the rampant spread of pneumonia like cases in the country. As many countries of the world have entered into an era of unlocking and practicing safer dentistry, it has become pivotal in understanding the protocols to be followed in preventing the Covid-19 infection. With a basic question in mind that how dental professionals should be practicing during COVID-19 pandemic, a survey was done to collect various protocols followed by dental professionals during implant surgery.

Methodology: It was a cross -sectional questionnaire based study carried out among the dental professional to assess the awareness, knowledge and practise towards implant protocols followed by dental professionals during covid-19 pandemic. Sampling was done by complete enumeration method and a total of 107 dental professionals were included in this study.

Result: A series of questions asked among the dental professionals drew various conclusions regarding the safety protocols and were assessed in terms of knowledge and understanding about protocols to be followed during implant surgery. Through this study it was found out that $64.5 \%$ of dental professional felt that it was safe to perform implant surgery during covid-19.

Conclusion and Clinical Implication: In the current study we have discussed the two aspects of impact of COVID19 outbreak on Implantology; first includes the knowledge and prevention of aerosols and second its clinical implications on Implant dentistry among dental professional.
\end{abstract}

Keywords: Covid-19, Dental Professional, Awareness, Implant Protocols.

\section{INTRODUCTION}

SARS-COV2, the virus also popularly known as the Coronavirus is an RNA- based virus that came to light in December 2019 when China informed the World Health Organization about the rampant spread of pneumonia like cases in the country. It was not very far after this news that on the $11^{\text {th }}$ of March, 2020, Covid-19 was declared as a pandemic and was considered as a public health crisis. ${ }^{1}$ 
This virus that causes COVID -19 infection, is thought to spread primarily between people who are often in close contact with one another i.e. within a distance of 6 feet or less. This infection spreads through respiratory droplets when an infected person coughs, sneezes or talks. The virus has been shown to persist in aerosols for hours, and by surface touch for days under laboratory conditions.

Dental health care professionals (DHCP) are at a great risk according to Occupational Safety and Health Administration (OSHA) and are placed at the highest risk category as dental professionals work in close proximity to patient's oral cavity. The Ministry of Health and Family welfare (MOHFW), India has formulated specific guidelines and given paramount importance to constantly updating them with the changing dynamics of the disease ${ }^{1}$

Various dental procedures that involve the production of aerosols with the widespread use of rotary dental and surgical instruments, such as handpieces or ultrasonic scalers and air-water syringes. ${ }^{2}$

In the recent times, dental implants are among the pre-eminent mode of dental services offered by majority of dentists worldwide.

During implant procedures the dental professionals encounter contaminated surfaces of instruments and aerosols that can serve as a potent source of viral transmission.

As many countries of the world have entered into an era of unlocking and practicing safer dentistry, it has become pivotal in understanding the protocols to be followed in preventing the Covid-19 infection.

Several papers, guidelines, reports and suggestions have been released in the year of 2020 on how this infection could be transmitted through dental services and what could be done.

With a basic question in mind that how dental professionals should be practicing during COVID-19 pandemic, a survey in the form of questionnaire has been made to collect various protocols followed by dental professionals during implant surgery.

\section{METHODOLOGY}

It was a cross -sectional questionnaire based study carried out among the dental professional to assess the awareness, knowledge and practise towards implant protocols followed by dental professionals during covid-19 pandemic.

Questionnaire consist of 2 SectionsSection A and Section B. Section A consist of Demographic details of the study participants e.g. Name, Age, Sex, educational qualification and current designation. Section $\mathrm{B}$ was further divided into Group A, Group B and Group C. Group A consists of 4 questions on awareness of Covid-19 infection, Group B consists of 6 questions on aerosol knowledge and prevention and Group C consists of 10 questions on practise towards implant protocols followed by dental professionals during covid-19 pandemic.

Questionnaire piloting was done on 10 dental professionals of Dhule district and the prepared survey questions were used for assessment of the awareness, knowledge and practise towards implant protocols followed by dental professionals during covid-19 pandemic. The sampling was done by complete enumeration method and a total of 104 dental professional around Khandesh and Mumbai region were included in this study. Informed consent was taken prior to the collection of data. Study included the dental professionals who were willing to take part in the study and incompletely filled questionnaire were excluded for the study.

The data collected from the questionnaire was entered on Ms Excel (2007 version developed by Microsoft) and was deployed on SPSS version 21 to carry out statistical analysis, descriptive statistics was used in the study. 
Champa Talreja et.al. A cross sectional study to assess the awareness, knowledge and practice towards implant protocols followed by dental professionals during Covid-19 pandemic.

\section{RESULT}

TABLE 1: Distribution of study participants.

\begin{tabular}{|l|l|l|l|}
\hline Variables & Male & N & Percentage \\
\cline { 2 - 4 } Sex & Female & 56 & 52.3 \\
\hline \multirow{2}{*}{ Education qualification } & BDS & 39 & 47.7 \\
\cline { 2 - 4 } & MDS & 68 & 63.6 \\
\hline
\end{tabular}

Table 1 shows that out of 107 study most were males $(52.3 \%)$ followed by females $(47.7 \%)$. Out of 107 most were the MDS as qualification were more $(63.60 \%)$ followed by BDS as qualification ( $36.40 \%)$

Table 2. Assessment of Awareness for covid

\begin{tabular}{|c|c|c|c|}
\hline \multicolumn{2}{|l|}{ Variables } & $\mathbf{N}$ & Percentage \\
\hline \multirow{4}{*}{$\begin{array}{l}\text { Do you follow the hand hygiene protocols given by WHO, whether it is an important measure } \\
\text { to prevent the risk of infection? }\end{array}$} & Strongly disagree & 4 & 3.7 \\
\hline & Disagree & - & - \\
\hline & $\begin{array}{ll}\begin{array}{l}\text { Neither agree or } \\
\text { disagree }\end{array} & \\
\end{array}$ & 77 & 72.0 \\
\hline & Agree & 26 & 24.3 \\
\hline \multirow[t]{4}{*}{ Whether $70 \%$ alcohol is the best method to sanitize the metallic objects? } & Strongly disagree & 5 & 4.7 \\
\hline & Disagree & 11 & 10.3 \\
\hline & $\begin{array}{ll}\text { Neither agree } & \text { or } \\
\text { disagree }\end{array}$ & 18 & 16.8 \\
\hline & Agree & 73 & 68.2 \\
\hline \multirow[t]{4}{*}{ Do you think, Dentist must use PPE Kit for every patient? } & Strongly disagree & 3 & 2.8 \\
\hline & Disagree & 9 & 8.4 \\
\hline & $\begin{array}{l}\text { Neither agree or } \\
\text { disagree }\end{array}$ & 44 & 41.1 \\
\hline & Agree & 51 & 47.7 \\
\hline \multirow[t]{4}{*}{ The standard mask that should be used by the dental practitioners are N95, N-100, FFP- 2 . } & Strongly disagree & 4 & 3.7 \\
\hline & Disagree & 2 & 1.9 \\
\hline & $\begin{array}{l}\text { Neither agree or } \\
\text { disagree }\end{array}$ & 55 & 51.4 \\
\hline & Agree & 46 & 43.0 \\
\hline
\end{tabular}

Table 2 shows the awareness and knowledge regarding covid guidelines and safety measures among dental professionals. Out of 107 many dental professionals neither agreed or disagreed (72\%) to follow the protocols given by WHO on hand hygiene. A large number of dental professionals (68.2) agree that $70 \%$ alcohol is the best method to sanitize the metallic objects. Around $47.7 \%$ dental professional's agree that dentist must use PPE Kit for every patient and $51.4 \%$ neither agreed or disagreed that the standard mask that should be used by the dental practioners are N95, N-100, FFP-2.

Table 3. Assessment Aerosol knowledge \& prevention

\begin{tabular}{|c|c|c|c|}
\hline \multicolumn{2}{|l|}{ Variables } & \multirow{2}{*}{$\begin{array}{l}\mathbf{n} \\
9\end{array}$} & \multirow{2}{*}{$\begin{array}{l}\text { Percentage } \\
8.4\end{array}$} \\
\hline \multirow{3}{*}{$\begin{array}{l}\text { Aerosol generating procedure minor oral surgical procedures should be } \\
\text { appointed at }\end{array}$} & First appointment of the day. & & \\
\hline & Last appointment of the day. & 93 & 86.9 \\
\hline & $0.2 \%$ Chlorhexidine. & 5 & 4.6 \\
\hline \multirow{4}{*}{$\begin{array}{l}\text { Pre and Post procedures mouthrinse is most affective in which of the } \\
\text { following solutions. }\end{array}$} & $1 \%$ hydrogen peroxide & 9 & 8.4 \\
\hline & $0.2 \%$ Povidine - Iodine & 55 & 51.4 \\
\hline & $0.2 \%$ Chlorhexidine. & 42 & 39.3 \\
\hline & $0.2 \%$ Chlorhexidine. & 1 & .9 \\
\hline \multirow{4}{*}{$\begin{array}{l}\text { Do you replace airotor with micromotor in order to reduce aerosol } \\
\text { production? }\end{array}$} & YES & 17 & 15.9 \\
\hline & $\mathrm{NO}$ & 35 & 32.7 \\
\hline & Sometimes, if required & 53 & 49.5 \\
\hline & Other & 2 & 1.9 \\
\hline \multirow{4}{*}{ What according to you is the proper sequence of donning, PPE. } & Gown, mask, face shield, gloves & 52 & 48.6 \\
\hline & Mask, gown, gloves, face shield & 34 & 31.8 \\
\hline & Gown, mask, gloves face shield & 18 & 16.8 \\
\hline & Others & 3 & 2.8 \\
\hline \multirow{3}{*}{ What according to you is the proper sequence of doffing PPE. } & Gloves, face shield, gown, mask & 56 & 52.3 \\
\hline & Gloves, gown, face shield, mask & 25 & 23.4 \\
\hline & Others & 26 & 24.3 \\
\hline \multirow{2}{*}{ Have you replaced your air conditioner with air purifier? } & Yes & 99 & 92.5 \\
\hline & No & 8 & 7.5 \\
\hline \multirow{4}{*}{ If yes, what is the micron size of the filtration membrane? } & $<0.18$ & 9 & 8.4 \\
\hline & $<0.12$ & 45 & 42.1 \\
\hline & $<0.3$ & 36 & 33.6 \\
\hline & $<0.5$ & 17 & 15.9 \\
\hline
\end{tabular}


Champa Talreja et.al. A cross sectional study to assess the awareness, knowledge and practice towards implant protocols followed by dental professionals during Covid-19 pandemic.

Table 3 shows the assessment regarding aerosol knowledge and prevention among dental health professionals. Out of 107 study participants most dental professionals $(86.9 \%)$ thought that aerosol generation procedures should be carried out as the last appointment of the day. Among the study participants $51.4 \%$ dental professionals agreed that $0.2 \%$ Povidine Iodine is the most effective Pre and Post procedures mouthrinse and $49.5 \%$ study participants replace their aerator with micromotor to reduce the aerosol load. Out of 107 study participants $48.6 \%$ and $52.3 \%$ knew the correct sequence of donning and doffing respectively.

Through this study we also found out that almost most of the dental professionals $(92.5 \%)$ have replaced their air conditioner with air purifier and $42.1 \%$ have used a filtration membrane of 0.12 micron size.

Table 4. Assessment of implant protocols

\begin{tabular}{|c|c|c|c|}
\hline \multicolumn{2}{|l|}{ Variables } & \multirow{2}{*}{$\begin{array}{ll}\mathbf{n} \\
69\end{array}$} & \multirow{2}{*}{$\begin{array}{l}\text { Percentage } \\
64.5\end{array}$} \\
\hline Do you feel it is safe to practice dental implant procedure during covid -19 & Yes & & \\
\hline & No & 38 & 35.5 \\
\hline \multirow[t]{4}{*}{ when should be fumigation done } & After every patient & 48 & 44.9 \\
\hline & at the end of the day & 59 & 55.1 \\
\hline & Not required & - & - \\
\hline & Others & - & - \\
\hline \multirow{3}{*}{$\begin{array}{l}\text { What according to you is the best method used for sterilization of implant procedure } \\
\text { instrument }\end{array}$} & U.V. chamber & 31 & 29.0 \\
\hline & Autoclave & 73 & 68.2 \\
\hline & chemical solutions & 3 & 2.8 \\
\hline \multirow{2}{*}{$\begin{array}{l}\text { Have you updated your dental suction unit next to the dental chair to help reduce aerosols } \\
\text { from implant and other dental procedures }\end{array}$} & Yes & 56 & 52.3 \\
\hline & No & 51 & 47.7 \\
\hline \multirow[t]{3}{*}{ If Yes, which of the following do you use? } & High volume evacuators & 66 & 61.7 \\
\hline & Saliva ejectors & 12 & 11.2 \\
\hline & High speed suction tips & 29 & 27.1 \\
\hline \multirow{3}{*}{$\begin{array}{l}\text { What according to you is the minimum exposure time safe to carry out an implant } \\
\text { procedure }\end{array}$} & 30 minutes & 67 & 62.6 \\
\hline & one hour & 40 & 37.4 \\
\hline & two hour & - & - \\
\hline \multirow{4}{*}{$\begin{array}{l}\text { What according to you is the recovery time for an implant procedure to be performed for a } \\
\text { covid positive patient }\end{array}$} & 14 to 20 days & 28 & 26.2 \\
\hline & 20 to 30 days & 35 & 32.7 \\
\hline & 3 months & 40 & 37.4 \\
\hline & Other & 4 & 3.7 \\
\hline \multirow[t]{4}{*}{ What do you feel is the safest procedure for implant surgery during covid times } & Flap surgical technique & 9 & 8.4 \\
\hline & $\begin{array}{l}\text { Flapless implant } \\
\text { procedure }\end{array}$ & 49 & 45.8 \\
\hline & $\begin{array}{l}\text { using implant surgical } \\
\text { guides }\end{array}$ & 48 & 44.9 \\
\hline & Other & 1 & .9 \\
\hline \multirow{3}{*}{$\begin{array}{l}\text { What according to you is the most efficient concentration of chlorhexidine as post } \\
\text { implant mouthwash to maintain oral hygiene }\end{array}$} & $0.2 \%$ & 47 & 43.9 \\
\hline & $2 \%$ & 39 & 36.4 \\
\hline & $1.2 \%$ & 21 & 19.6 \\
\hline \multirow{2}{*}{$\begin{array}{l}\text { Have you incorporated augmented ventilation (exhaust fans and windows) instead of air } \\
\text { conditioners to decrease aerosol contamination during implant procedure }\end{array}$} & Yes & 67 & 62.6 \\
\hline & No & 40 & 37.4 \\
\hline \multirow[t]{3}{*}{ What aerosol adjuvants have you installed for minimizing aerosol production } & Fogger & 54 & 50.5 \\
\hline & $\begin{array}{l}\text { UVGI (Ultraviolet } \\
\text { Gamma Irradiation) }\end{array}$ & 38 & 35.5 \\
\hline & Negative ion Generation & 15 & 14.0 \\
\hline
\end{tabular}

Table 4 shows assessment regarding implant protocols amid covid-19. Out of 107 study participants $64.5 \%$ dental professionals thought that it is safe to practice implant dentistry during covid 19. To the various questions asked about the safety protocols $55.1 \%$ said the fumigation procedure for dental clinics should be done at the end of the day and $68.2 \%$ dental professionals were with the view that autoclave is the best method used for sterilization of implant procedure instrument. When asked about procedures to reduce aerosol production during implant procedures $52.3 \%$ dental professionals have updated their dental suction units and it was seen that $61.7 \%$ dental professionals used high volume evacuators, $11.2 \%$ used saliva ejectors and $27.1 \%$ used high speed suction tips to reduce aerosol load during implant procedures and other minor oral surgical procedures. Some dental professionals 
(37.4\%) feel that the minimum exposure time safe to carry out implant procedure is 1 hour while others $(62.6 \%)$ feel a minimum time of 30 minutes is safe.

There is a less clear understanding among dental professionals regarding the recovery time for an implant procedure to be performed for a covid positive patient. $26.2 \%$ study participants feel that it should be 14 to 20 days, $32.7 \%$ said 20 to 30 days while the rest $37.4 \%$ feel the recovery time should be around 3 months.

The safest procedure according to $45.8 \%$ dental professionals in this study is the flapless implant surgical technique and $44.9 \%$ had an opinion that the use of surgical guides is the safest procedure for implant surgery.

Knowledge about the disinfectant concentration was assessed and it was found that $43.9 \%$ study participants agreed that $0.2 \%$ was the most effective concentration of chlorhexidine as post implant mouthrinse to maintain oral hygiene. It was found out that of the total study participants $62.6 \%$ have incorporated augmented ventilation instead of air conditioners whereas $50.5 \%$ dental professionals have installed fogger to decrease aerosol contamination during implant procedure.

\section{DISCUSSION}

As it is a matter of the end of the pandemic will have to mark the beginning of new methods of approach and management in dental practise. ${ }^{3}$

Coronaviruses $(\mathrm{CoVs})$ belong to the subfamily Orthocoronavirinae in the family Coronaviridae, Order Nidovirales. There are four genera within the subfamily Orthocoronavirinae, namely Alphacoronavirus ( $\alpha-\mathrm{CoV})$, Betacoronavirus $(\beta-\mathrm{CoV})$, Gammacoronavirus $(\gamma-\mathrm{CoV})$ and Deltacoronavirus $(\delta-\mathrm{CoV})$.

019-nCoV29. 2019-nCoV possesses the typical coronavirus structure with the "spike protein" in the membrane envelope30, and also expresses other polyproteins, nucleoproteins, and membrane proteins, such as RNA polymerase, 3- chymotrypsin-like protease, papain-like protease, helicase, glycoprotein, and accessory proteins. ${ }^{4}$

COVID-19 pandemic has been a dreadful experience and has led to an array of medico-legal and professional concerns for dentist in India and around the globe in terms of patient care provisions. Due to this, the government, and the World Health Organisation and the Dental Council of India (DCI) have promulgated guidelines on the aspect of appropriate patient management principles during the pandemic 5

During this pandemic crisis, clinics with emergency care must follow stringent measures recommended by the local and regional health authorities to minimize risks of disease transmission and increase measures taken for its prevention ${ }^{6}$

Majority of dental and prosthodontic procedures involve close physical contact with the patient generating aerosols increasing the risk of viral transmission. In the absence of clinical studies, the most important challenge in performing oral antisepsis is to find the effective concentration of solution used and duration of topical preparations which are safe to administer. $^{7}$

This study provides an insight on the level of knowledge, attitude and preparedness of heath care professional towards performing implant surgical procedures during the times of COVID-19.

\section{AEROSOL REDUCTION}

Out of 107 study participants most dental professionals $(86.9 \%)$ thought that aerosol generation procedures should be carried out as the last appointment of the day

When performing aerosol generating procedures (using air-water syringe, ultrasonic scaler and high-speed handpiece), a type of respirator that is at least as protective as a National Institute for Occupational Safety and Health (NIOSH)certified N95, European Standard Filtering Face Piece 2 (EU FFP2), or equivalent, 
should be used. When performing emergency dental treatment with suspected COVID-19 cases, a higher level of respiratory protection should be considered, such as EU FFP3 respirators conforming to European Standard 149 (EN149). ${ }^{8}$

\section{MOUTH RINSE}

Among the study participants $51.4 \%$ dental professionals agreed that $0.2 \%$ Povidone-Iodine is the most effective Pre and Post procedures mouthrinse and $49.5 \%$ study participants replace their aerator with micromotor to reduce the aerosol load. Knowledge about the disinfectant concentration was assessed and it was found that $43.9 \%$ study participants agreed that $0.2 \%$ was the most effective concentration of chlorhexidine as post implant mouthrinse to maintain oral hygiene

One of the most effective methods of reducing the proportion of microorganisms in oral aerosols is the pre-procedural mouth rinse (Samaranayake and Peiris, 2004; Feres et al., 2010). A meta-analysis carried out by Marui et al., 2019 showed that the use of preprocedural mouth rinse, including chlorhexidine (CHX), essential oils, and cetylpyridinium chloride (CPC), resulted in a mean reduction of $68.4 \%$ colony-forming units in dental aerosol. It has been proven by Wood and Payne, 1998 that CHX is effective against several infectious viruses, including human immunodeficiency virus (HIV), herpes simplex virus (HSV), and hepatitis B virus (HBV). But the effect of preprocedural mouth rinse against coronavirus is still unknown. About $0.12 \%$ CHX was used as a preprocedural mouth rinse. According to Feres et al., 2010for patients who develop mucosal irritation or other side effects such as tongue stain, $0.05 \%$ CPC could be a good alternative.

\section{HEPA FILTER}

Through this study we found out that almost most of the dental professionals $(92.5 \%)$ have replaced their air conditioner with air purifier and $42.1 \%$ have used a filtration membrane of 0.12 micron size.
It was found out that of the total study participants $62.6 \%$ have incorporated augmented ventilation instead of air conditioners whereas $50.5 \%$ dental professionals have installed fogger to decrease aerosol contamination during implant procedure.

To the various questions asked about the safety protocols $55.1 \%$ said the fumigation procedure for dental clinics should be done at the end of the day and $68.2 \%$ dental professionals were with the view that autoclave is the best method used for sterilization of implant procedure instrument. When asked about procedures to reduce aerosol production during implant procedures $52.3 \%$ dental professionals have updated their dental suction units and it was seen that $61.7 \%$ dental professionals used high volume evacuators, $11.2 \%$ used saliva ejectors and $27.1 \%$ used high speed suction tips to reduce aerosol load during implant procedures and other minor oral surgical procedures

Several methods to remove/filter contaminated air in treatment areas have been accounted by surveying dental professionals out of them the two most commonly used devices include the inexpensive high volume evacuator (HVE) and the expensive high efficiency particulate arrestor (HEPA) filters.

Through this study it was found that $49.5 \%$ study participants replaced their aerator with micromotor to reduce the aerosol load.

Studies have shown that the use of high-speed turbines with anti-retraction valve has significantly reduced the return flow of oral bacteria ${ }^{9}$

Specially designed anti-retractive valves in anti-retraction dental handpiece or other anti-reflux designs are strongly recommended as an extra preventive measure for crossinfection ${ }^{10}$

- HVE filter: According to Narayana et al., 2016- It is a suction device that helps remove air at a rate of up to $2.83 \mathrm{~m} 3$ per minute. Studies have shown that it is the easiest way to remove dental aerosols as 
they are generated and could effectively reduce contamination caused by the operating site by $90 \%$

- However, when in use the device should be held at a proper distance at approximately $6-15 \mathrm{~mm}$ from the active ultrasonic tip. But one limitation of the HVE is that without the help of a dental assistant, clinicians might face difficulty in operating it. Modified HVEs are available in the market that addresses this problem.

- HEPA filter: It is an air filtration device that can remove $99.97 \%$ of the particles measuring $0.3 \mu \mathrm{m}$ in diameter.

- One major disadvantage is that the filter may become a source of microbes if the retained microorganisms proliferate and enter back into the filtered air ${ }^{11}$

\section{PPE}

Around $47.7 \%$ dental professional's agree that dentist must use PPE Kit for every patient and $51.4 \%$ neither agreed or disagreed that the standard mask that should be used by the dental practitioners are N95, N-100, FFP-2.

Out of 107 study participants $48.6 \%$ and $52.3 \%$ knew the correct sequence of donning and doffing respectively.

The protection of our frontline health workers is of prime importance and PPE, including medical masks, respirators, gloves, gowns, and eye protection, must be prioritized for health care workers and others looking after for COVID-19 patients. 12

The type of PPE used when caring for COVID-19 patients will differ according to the setting, and type of personnel, and activity.

- According to Indications, Specifically, for aerosol-generating procedures and support treatments (tracheal intubation, noninvasive ventilation, tracheotomy, cardiopulmonary resuscitation, manual ventilation before intubation, and bronchoscopy) Health care workers should use PPE respirators, eye protection, gloves and gowns; ${ }^{12}$
- In the absence of aerosol generating procedures -Medical mask, Gown, Gloves, Eye protection (goggles or face shield), Perform hand hygiene.

- In case of direct care to patients in settings where aerosol generating procedures are frequently in place, Respirator N95 or FFP2 or FFP3 standard, or equivalent should be used along with gown, gloves, eye protection, apron, perform hand hygiene.

- Dental Assistant should consider the use of medical mask, gown, heavy-duty gloves, eye protection (if risk of splash from organic material or chemicals is anticipated), closed work shoes and perform hand hygiene.

- Professionals Handling and processing of specimens from cases with suspected or confirmed COVID-19 infection that are expected for additional laboratory tests, such as haematology or blood gas analysis, should apply standard precautions and make use of medical mask, eye protection, gown, gloves, perform hand hygiene. ${ }^{12}$

\section{IMPLANT PROCEDURE PROTOCOLS:}

The million dollar question which arise here is, precautions pertaining to covid19 that are deemed necessary by the implantologist for a bilaterally safe procedure

It is of paramount importance presently to consider every patient as a potential carrier of the virus and thus treat accordingly. It has become almost compulsory in current scenario to use WHO recommended guidelines and PPE kits ${ }^{13}$

Some dental professionals $(37.4 \%)$ feel that the minimum exposure time safe to perform implant procedure is 1 hour while others $(62.6 \%)$ feel a minimum time of 30 minutes is safe.

There is a less clear understanding and knowledge among dental professionals regarding the recovery time for an implant 
procedure to be performed for a covid positive patient.

$26.2 \%$ study participants feel that it should be 14 to 20 days, $32.7 \%$ said 20 to 30 days while the rest $37.4 \%$ feel the recovery time should be around 3 months.

Since the incubation period of SARS-CoV-2 may extend over 2 weeks, a positive response any of the above queries commands deferring the appointment for at least 2 weeks. Additionally, the patients should be motivated to self quarantine at home and contact their primary care physician for tele-consultation. ${ }^{13}$

At the appointment visit, patients should be asked to fill out detailed questionnaire regarding their medical history, Covid-19 screening as well as a true emergency questionnaire.

The safest procedure according to $45.8 \%$ dental professionals in this study is the flapless implant surgical technique and $44.9 \%$ had an opinion that the use of surgical guides is the safest procedure for implant surgery.

During surgery, slow speed drilling with sharp drills is favoured. Intermittent external irrigation along with high volume suction should be achieved. Use of ultrasonic devices and piezoelectric surgery should be reduced; whereas use of osteotomes should be encouraged in order to decrease aerosol formation.

Immediate implants with immediate loading should be taken up wherever indicated as they require lesser time and less number of visits. It is judicious to avoid complex full mouth procedures. Digital impression with scan bodies is suggested as an alternative to conventional impression making can be used and a flapless implant surgical procedure will help minimize the risk of aerosol production. Implant impressions and components need to be carefully disinfected/autoclaved before reusing them. Imaging procedures should use extraoral techniques incuding panoramic radiography or computed tomography to avoid contact with oral secretions and minimise gag/cough reflex ${ }^{13}$
The post operative sequelae of implant surgery involve the metabolic response of soft tissue and alveolar bone surrounding the implant site. Viruses pose significantly higher health risk and put an extra strain on host immune system, which in turn has an adverse effect on the bone marrow. This successively may cause bone marrow pathology, eventually resulting in compromised healing from implant surgery ${ }^{13}$

In light of available literature, the prognosis on dental implant associated procedures remains guarded in patients infected with SARS-CoV-2 virus.

\section{CONCLUSION}

Famously said that saliva is the colourless carrier of corona hence prevention of oral health worldwide represents the gold standard towards which health care professionals in dentistry should always be oriented.

As the entire world is coping with the pandemic in two major fronts one being health care and second economy, dentistry and its sub stream of implantology isn't spared from the same, the speculations and certainty are going hand in hand about impact of COVID19 outbreak on Implantology. In the current study we have discussed the two aspects of impact of COVID19 outbreak on Implantology; first includes the knowledge and prevention of aerosols and second its clinical implications on Implant dentistry among dental professional.

At the end it can be safely concluded that the covid-19 outbreak is going to cause a drastic paradigm shift in business and health care for sure. In such a scenario it is no surprise that Dental Implantology being an amalgamation of both the abovementioned sectors will definitely not remain untouched. ${ }^{13}$

\section{Acknowledgement: None}

Conflict of Interest: None 
Source of Funding: None

\section{Ethical Approval: Approved}

\section{REFERENCES}

1. Pruthi G, Parkash H, Vijaya Bharathi P, Jain R, Gupta A, Rai S. Comprehensive review of guidelines to practice prosthodontic and implant procedures during COVID-19 pandemic. Journal of oral biology and craniofacial research. 2020 Oct;10(4):768

2. Centers For Disease Control And Prevention Guidelines on https://www.cdc.gov/coronavirus/2019ncov/hcp/dental-settings.html

3. COVID $19 \quad$ PROTOCALS https://www.ida.org.in/pdf/Covid19-IDAProtocol.pdf

4. Peng X, Xu X, Li Y, Cheng L, Zhou X, Ren B. Transmission routes of 2019-nCoV and controls in dental practice. Int J Oral Sci. 2020 Mar 3;12(1):9

5. Kinariwala N, Samaranayake LP, Perera I, Patel Z. Concerns and fears of Indian dentists on professional practice during the coronavirus disease 2019 (COVID-19) pandemic. Oral diseases. 2020 Jun 7

6. Pan Y, Liu H, Chu C, Li X, Liu S, Lu S. Transmission routes of SARS-CoV-2 and protective measures in dental clinics during the COVID-19 pandemic. Am J Dent. 2020 Jun;33(3):129-134. PMID: 32470237

7. Bidra AS, Pelletier JS, Westover JB, Frank S, Brown SM, Tessema B. Rapid in-vitro inactivation of severe acute respiratory syndrome coronavirus 2 (SARS-CoV-2) using povidone-iodine oral antiseptic rinse. Journal of Prosthodontics. 2020 Jul;29(6):529-33

8. Ge ZY, Yang LM, Xia JJ, Fu XH, Zhang YZ. Possible aerosol transmission of COVID19 and special precautions in dentistry. Journal of Zhejiang UniversitySCIENCE B. 2020 Mar 16:1-8.

9. Luzzi V, Ierardo G, Bossù M, Polimeni A. Paediatric Oral Health during and after the COVID-19 Pandemic. Int J Paediatr Dent. 2021 Jan;31(1):20-26. doi: 10.1111/ipd.12737. Epub 2020 Oct 16. PMID: 33012056; PMCID: PMC7675493.

10. Peng X, Xu X, Li Y, Cheng L, Zhou X, Ren B. Transmission routes of 2019-nCoV and controls in dental practice. International journal of oral science. 2020 Mar 3;12(1):16.

11. Ge ZY, Yang LM, Xia JJ, Fu XH, Zhang YZ. Possible aerosol transmission of COVID19 and special precautions in dentistry. Journal of Zhejiang UniversitySCIENCE B. 2020 Mar 16:1-8

12. Rational use of personal protective equipment for coronavirus disease (COVID19) and considerations during severe shortages: interim guidance. This work is available under the CC BY-NC-SA 3.0 IGO licence. WHO reference number: WHO/2019-nCov/IPC_PPE_use/2020.3

13. Abhimanyu Sharma, Dhirendra Srivastava, Lokesh Chandra and Sonal Mishra (2020) ' Future of Implants in Dentistry Post Covid19 Pandemic', International Journal of Current Advanced Research, 09(06), pp. 22504-22507

14. Deery C. The COVID-19 pandemic: implications for dental education. Evidencebased dentistry. 2020 Jun;21(2):46-7.

15. Bhanushali P, Katge F, Deshpande S, Chimata VK, Shetty S, Pradhan D. COVID19: Changing trends and its impact on future of dentistry. International journal of dentistry. 2020 May 29;2020

16. Ali khan, Shobha Joshi, Rutuj Waghmare, Reena Rani, Shreya Srivastava ,Tejas Kadam, Jyoti Raghuvanshi, Mantasha Khan A cross- sectional study on knowledge, attitude and preparedness of dental health care professional towards ppe (personal protective equipment) and decontamination protocol during covid-19 among vidarbh region. European journal of pharmaceutical and medical research july2020 7(7):675680

17. Chang TY, Hong G, Paganelli C, Phantumvanit P, Chang WJ, Shieh YS, Hsu ML. Innovation of dental education during COVID-19 pandemic. Journal of Dental Sciences. 2021 Jan 1;16(1):15-20.

18. Fini MB. What dentists need to know about COVID-19. Oral oncology. 2020 Apr 28:104741

19. Waghmare R, Khan A, Joshi S, et al. A cross-sectional study on awareness and knowledge regarding covid 19 spread, appropriate protocol for prevention and future preparedness among dental health care workers. IJMAS. 2020; 9 (1).

20. Lu H, Stratton CW, Tang YW. Outbreak of pneumonia of unknown etiology in Wuhan, 
Champa Talreja et.al. A cross sectional study to assess the awareness, knowledge and practice towards implant protocols followed by dental professionals during Covid-19 pandemic.

China: the mystery and the miracle. Journal of medical virology. $2020 \mathrm{Apr} ; 92(4): 401-2$

21. Ministry of Health and Family Welfare Directorate General of Health Services [Emergency Medical Relief] Novel Coronavirus Disease 2019 (COVID-19): Guidelines on rational use of Personal Protective Equipment. Available on https://www.mohfw.gov.in/pdf/Additionalg uidelinesonrationaluseofPersonalProtective EquipmentsettingapproachforHealthfunction ariesworkinginnonCOVIDareas.pdf

22. Hospital infection control guidelines. Available at https://www.ijmm.org/documents/Hospital_ Infection_control_guidelines.pdf

23. Ather A, Patel B, Ruparel NB, Diogenes A, Hargreaves KM. Coronavirus disease 19 (COVID-19): implications for clinical dental care. Journal of endodontics. 2020 May 1;46(5):584-95.
24. Marwaha J, Shah K. Safety \& preventive measures for dental health care professionals on COVID-19. International Journal of Science and Healthcare Research. 2020;5(2):1-4.

25. Wu Z, McGoogan JM. Characteristics of and important lessons from the coronavirus disease 2019 (COVID-19) outbreak in China: summary of a report of 72314 cases from the Chinese Center for Disease Control and Prevention. Jama. 2020 Apr 7;323(13): 1239-42

How to cite this article: Talreja C, Issac S, Nagaral S et.al. A cross sectional study to assess the awareness, knowledge and practice towards implant protocols followed by dental professionals during Covid-19 pandemic. Int $J$ Health Sci Res. 2022; 12(3):44-53. DOI: https://doi.org/10.52403/ijhsr.20220307 